\title{
How Did We Do? Beginning teachers teaching mathematics in primary schools
}

Sandy Schuck*

University of Technology, Sydney, Australia

*Email: sandy.schuck@uts.edu.au

This article examines the findings of a research program that investigated primary school mathematics teaching by graduates of the teacher education program at the University of Technology Sydney. The research comprised two distinct studies, one examining the experiences of student teachers in our teacher education program and the other considering the experiences of our graduates once they began to teach. I focus on what I learnt from these studies, particularly on the second one that highlights dilemmas faced by teacher educators when preparing their students for the realities of the classroom. I discuss the overwhelming nature of the experience of the first year of teaching and argue for more support from teacher educators for helping their graduates in those early days of teaching.

Keywords:

In this paper I interrogate a research program conducted over a number of years to ascertain what I could learn about our primary teacher education program and, in particular, about the primary mathematics education that we offer to students at the University of Technology Sydney. While I did not track the same group of participants from their student years into the early years of teaching, I view this program of research as a longitudinal set of studies. Student teachers' learning and the experiences of our graduates are seen as points along a continuum of teacher education and development. One of my aims concerned self-study and focused on what 
I could learn that might be of value in enhancing my existing teacher education courses and in developing others. I also wished to consider more broadly what happens when beginning teachers who have experienced teacher education embedded in a reform philosophy of teaching and learning begin to make decisions about how they will teach mathematics within the constraints of the primary school.

The first phase of the research included an examination of the philosophies and assumptions of the mathematics teacher educators in our primary education program and how these influenced the content and approaches used in the mathematics education courses. It also included an investigation of students' beliefs about mathematics education during their studies. The second phase of the research investigated our graduates' early teaching experiences through analyses of their reflective journals, their participation in supportive workshops and interviews. In this article, my primary focus is on the experiences of our students after they became teachers in primary schools. Their first year of teaching provided me with many insights as to how we might better prepare them in our teacher education courses, in addition to providing an indication of their experiences as beginning teachers.

An important document produced by the National Council of Teachers of Mathematics (NCTM, 2000) calls for teachers to take a fresh approach to the teaching of mathematics (Nisbet \& Warren, 2000). Reform initiatives targeting the teaching of mathematics in schools are commonplace, and many teacher education courses for primary school teachers seek to challenge the beliefs of student teachers about both pedagogy and mathematics content (Walshaw \& Anthony, 2007). There seems to be little evidence, however, that these initiatives have resulted in much change. Indeed, recent studies note that primary school teachers generally suffer from a lack of preparedness to teach mathematics (Angus, Olney, \& Ainley, 2007) and primary school teachers report a lack of awareness of suitable activities for responding to learner diversity (Lyons, et al., 2006). Teaching mathematics in primary schools has always been perceived as a difficult task (Schuck, 1996), and the difficulty is exacerbated 
by the processes of re-learning required if teachers are to learn to teach mathematics in new and different ways.

My focus on the teaching of mathematics occurred because of the paradoxical ways in which this subject is known to primary school teachers. While most primary school teachers appreciate the importance of mathematics in the primary education curriculum, many feel completely unprepared to teach it (Angus, Olney \& Ainley, 2007). This perception of the primacy of mathematics, together with a lack of confidence in the ability to teach it, often leads to methods of teaching that emphasize procedure over understanding (Nisbet \& Warren, 2000). Through this research I sought to enhance my own and others' understanding of the paradox in such views and practices in primary schools. I hoped to suggest ways in which teachers can become more effective in teaching mathematics. I also wished to provide teacher educators with more sophisticated insights into the ways in which mathematics teacher education can assist student teachers' understanding of the influences that bear directly on decisions they will make in their future teaching practice.

\section{Design of the Study}

The research has two distinct phases. The first phase was located in the university and investigated student teachers' beliefs about mathematics and mathematics teaching and learning. This phase also considered the ramifications of such beliefs on student teachers' perceptions of the teacher education subjects in mathematics education and on their future practice as teachers in primary schools. It explored the ways in which student teachers experienced these subjects against the backdrop of their previous life experiences and the associated assumptions about the nature of mathematics. Also in this phase, teacher educators' philosophies and approaches were examined for their fit with notions of reform in mathematics education and for their influence on and alignment with the attitudes and beliefs of student teachers (Schuck, 2002).

The second phase investigated the experiences of the program's graduates as they started teaching mathematics in primary schools. I investigated how the beginning teachers met the 
challenges of teaching mathematics within a context of constraints arising from the nature of the subjects being taught, the life histories of the participants in these subjects, the participants' new learning about the teaching of these subjects and the participants' interactions, as beginning teachers, with school, community and colleagues. The major aims of this study were to understand beginning teachers' experiences and meaning-making as they started implementing reform notions of mathematics teaching in their classrooms and to gain insights into the impact of preservice mathematics education experiences on the preparation of confident and competent primary school teachers in mathematics.

\section{Research Plan}

The research studies were embedded in a qualitative research paradigm. The rigour of each phase of the study was guided by criteria of resonance, rhetoric, empowerment and applicability as enunciated by Lincoln and Guba (1990). The first phase investigated student teachers' beliefs about mathematics education using a grounded-theory methodology in which all the students from the first-year primary education cohort devised and posed an initial set of questions to each other on attitudes and beliefs about mathematics teaching and learning. I then analyzed both students' questions and their responses to each other, using open-coding techniques (Strauss \& Corbin, 1998), memoing, and the constant-comparison method (Bogdan $\&$ Biklen, 1998) to look for recurrent themes that indicated the central issues for the student teachers. These themes served as the basis for an open-ended survey and an interview schedule for a smaller sample of the respondents who had been purposefully selected (Bogdan \& Biklen, 1998) because they had demonstrated an interest in self-reflection in the earlier data collection. In these interviews I explored the issues put forward by the students, such as their personal philosophies of mathematics, their feelings about mathematics, their views on the relevance of mathematics in general, and their beliefs about mathematical ability. I kept these interviews largely unstructured to capture their voices rather than mine. The final part of this phase included interviews with the mathematics education staff, including a recorded interview, in 
which I posed the same questions and answered them myself, about our underlying philosophies and beliefs about mathematics education. All data were analyzed through a combination of open-coding techniques (Strauss \& Corbin, 1998), memoing, and indexing of texts (Miles \& Huberman, 1994). As the study progressed, this analysis fed into subsequent data collection in keeping with the grounded-theory methodology (Strauss \& Corbin, 1998). A framework for understanding student teachers' beliefs and attitudes was developed.

The second phase of the research program explored the experiences of seven beginning teachers in their first year of teaching. Although all were graduates of our teacher education program, they were not the same group that participated in the first phase. They were volunteers who had graduated from our program the previous year and had been successful in obtaining positions in schools. The teachers participated in three workshops that provided them with an opportunity to meet with each other and share experiences. All discussions were taped and then transcribed. In addition, the participants were given a choice of media to provide additional information about their experiences throughout the first year. One chose to provide us with her reflective journal, while the others chose to have a regular phone call (weekly or fortnightly over a period of approximately 10 weeks) with me or a co-researcher to discuss critical incidents that had occurred during the week, as well as reflections on the approach, constraints, challenges, and facilitating factors that occurred during their lessons. The data were analyzed through date reduction, coding and an examination of either recurrent themes or unusual data that might inform understanding of their lives as beginning primary school teachers.

\section{Self-Study Component}

Both phases of this program of research had a strong self-study component. In the first phase, I ensured that I would respond to the same set of questions as the other mathematics educators in an attempt to interrogate my philosophies and their fit with student beliefs and attitudes. I audiorecorded these responses for future analysis. The analysis of the data from both students and lecturers was aimed at informing my preparation of the mathematics education subjects. Self- 
study also led to the development of the second phase of research as I considered how best to evaluate my own teaching.

The second phase of the research was designed to provide insights into what was useful, what might be irrelevant, or what was responsible for creating tensions for new teachers. Hence the data were used to suggest ways forward for my teaching and, because I serve as program coordinator, for the development of all the mathematics education subjects in the program. Thus the major intent of this research was to develop a process whereby teacher educators can learn from their graduates.

\section{Relevant Findings}

Many of my findings in the first phase have been documented in earlier studies and articles (Schuck, 1998, 1999, 2002). To summarize, many student teachers in the primary education courses had not had positive experiences in secondary school and were determined to ensure that their students had better experiences. However, the route to better experiences often did not lie in the teachers' development of their subject knowledge but rather in the provision of enjoyable activities that were often weak from the perspective of the conceptual development of mathematical ideas. The startling idea that prospective teachers often felt that being knowledgeable about the subject matter in mathematics classes would make them less effective as primary school teachers led to calls (e.g., Jones, 2004) for investigations to follow these students into their early years of teaching.

Phase two findings centred on the aspects of the teacher education program that did not appear to sufficiently support teachers in their early years, including views of teachers about their classes and their teaching of mathematics and the overwhelming nature of the first year of teaching.

Views of Being a New Teacher of Mathematics in the Primary School

Beginning teachers took their new role as teacher very seriously, including their feelings about teaching mathematics. While being somewhat fearful about their ability to teach this subject 
well, they also understood the importance of their students' affective responses to the subject. In the first workshop, some 2 months after teachers had begun their first year of teaching, participants were asked to choose a photograph to best represent their feelings about teaching mathematics. One participant chose a picture of an elephant with a little girl leaning against the animal.

At the moment I feel like the elephant when thinking about teaching mathematics, due to the fact that elephants are huge creatures and with one mistake or slight accident I could crush the child. With my mathematics teaching, if I make the wrong comment or teach mathematics in a way that doesn't work for the child, I could crush the child's enthusiasm for mathematics or do something to make them very wary and never again trust me or be as open with me or feel as willing to try something unfamiliar. (Julie, first workshop)

Another participant who also chose the elephant picture noted that:

In maths especially, ... I would ideally like to be someone the kids lean on for support during their learning process.... I would love to be the support figure, someone to lean on for learning support. Hopefully, I will achieve this sometime during the year. (Annie, first workshop)

A participant who chose a picture of a child's hand in an adult's hand said:

I like the way the palms are facing upward, which is receptive. I also like the way that the child's hand is being gently supported by the adult's hand. In this way, the child is not being controlled by, or smothered by, the adult. Rather, the adult is there as a support to the child. ... This is something which I would like to achieve with my class, but often lose sight of as the daily pressures mount. (Chrissie, first workshop) In these responses, support for students' learning is paramount. A second theme involved the desire to be a facilitator of learning in the way we had discussed in education classes. Annie expressed concern that she might not be doing justice to this idea: "Some days I 
know I revert to the old autocratic figure, but when I let kids explore on their own, I am not sure whether they are learning the important concepts they are supposed to [learn]." (Annie, first workshop)

The teachers noted their concern and caring about their teaching in a way that indicated their idealism. However, I would argue that idealism does not always serve its owner well. I am concerned that the rough and tumble of the classroom might destroy their idealism and that, without it, they are ill-prepared for the realities of teaching. I need to think more about how I can prepare my students to withstand blows to their idealistic aspirations as they enter the school. I must challenge my taken-for-granted assumption that idealism should be fostered and not in any way disrupted by our teacher education program.

\section{Barriers and Constraints}

My concerns about whether to foster this idealism or not are related to the next issue that arose in the data. The school context often seems to provide barriers to our graduates' teaching in the ways we have discussed at university. One example of this tension has been reported in detail (Schuck, 2006) and concerned the desire of our graduates to teach in interactive and experiential ways, as proposed in our education classes. However, one participant (Julie) reported in her interviews that she was becoming increasingly frustrated and feeling that she was failing as the teacher she wanted to be because of the situation with textbooks in the school. Based on the decision of the coordinator at the end of the previous year, the school had asked the parents to buy a workbook for their children. Julie, fresh with ideas about authentic learning and childcentred activities, found that she was obliged to work on one page of the workbook each day with her students so that parents would not feel that their money had been wasted. Ensuring that each child completed the page meant that all the time set aside for mathematics each day was used up in this activity, leaving her no time for other activities. The tensions of following a procedure that Julie did not see as pedagogically valuable, coupled with the lack of opportunity to put her own ideas into play, led to feelings of failure and dismay for Julie. 
Another example of practice we had encouraged in our classes also led to some tension and feelings of inadequacy by Annie. About 3 months into her first year of teaching, she told me about how motivated her students had been when taken to see a science show where the presenters made a cake and, through the process, discussed a number of scientific concepts.

The children were so excited and motivated to do things and I was thinking "I've got to do more of this stuff with them." ... Of course, during term I got sick again and couldn't get organized and I'd find everything else [to do rather than this activity]. . . I kept putting it off and putting it off and then, before I knew it, the term was over and I hadn't done it. I felt really bad about it. (Annie, second interview)

She went on to say that they had done such activities at university and she could see that the students had really developed a good understanding of the concepts as a result.

But I couldn't even get to the point of sitting down and thinking about what I wanted to do. The whole thing really got away from me. . . I can make all the excuses but it came down to the fact that I didn't have the energy. (Annie, second interview)

Annie had a child with an acute behaviour disorder in her class. She found that all of her energy went into trying to manage this child, to the detriment of the other children in her class. The struggle to work with the child sapped her energy and she was sick quite often. Another consequence of having this child in her class was that she abandoned her mathematics groups. She did so because this one child was very destructive when in a group situation, worse than in other situations. The other children were very disappointed that they were not continuing with their groups. Annie also noted that her class was falling behind the parallel class, which was taught by the Deputy Principal, and was "beautifully behaved."

These are just three of a number of examples indicating that teachers were having difficulty in fulfilling what they saw as university staff expectations for them, expectations they had subsequently internalized. Many respondents' comments offered incidents similar to these three. The incidents and resulting comments seemed to indicate feelings of guilt and of failing 
to measure up to an idealized image of the good teacher. The new teachers highlighted how easy it is for teacher educators to suggest teaching models and good practices far away from the constraints of the classroom. As Buchanan (2006) suggested, in a tertiary context, our students, our teaching, and our behavioural expectations of our students are likely to be far less problematic than their equivalent counterparts in schools.

Another barrier appeared to be the differing emphasis that we put on the three major strands of the mathematics curriculum. The curriculum includes the three major areas of Number, Space (Geometry) and Measurement. Other areas have also been introduced, such as Chance and Data. This curriculum differed from the previous one, which emphasized arithmetic and only paid glancing attention to the other areas. Jenny found this to be a problem when she started teaching: "I had just assumed that Number was just as important as the other two, and it's obviously not by this school's philosophy of things. It's far more important." She went on to say that the interview process had led her to reframe her thinking about this emphasis:

I would have just brushed it off and thought "Stupid school making me do this" but, now that I have had a talk with you, I have to think "Well, why are they making me do this?" and especially the last 2 weeks when I thought, "Now I know why they are making me do it," and it seems to have improved my attitude. (Jenny, final interview)

Notably, it appears that our teacher-educator convictions that our approaches and content were the most appropriate appeared to permeate the learning experience of our students. These ideas may have set up our graduates to feel impatient with, and consequently resistant to, the demands of the school.

\section{Understanding Mathematics}

A final issue that arose and confirmed earlier findings (Schuck, 1999) was the lack of understanding that some of the beginning teachers displayed about the subject matter and the purpose of various lessons. Having fun in the mathematics classroom continued to be extremely 
important, sometimes at the cost of the development of deep conceptual understandings. This confirmed the findings of the first phase of the study. For example, Jenny reported that she had children working with blocks in mathematics. The textbook exercise was to count the number of blocks in a drawing, but when the children found this difficult, Jenny had them build the constructions and then count the blocks. From there they were better able to see how to work out the number of blocks in the diagram. Jenny was quite pleased at how the lesson had gone and how she had used ideas from the teacher education course to clarify the activity. She reported that the children had really enjoyed building with the blocks and "the lesson had been a lot of fun. The students are getting really involved in maths as I make it so much fun.” However, when I asked for what mathematical idea the activity was preparing the children, she was not sure. "I looked it up and it was Space 3D Unit 4" (Jenny, second interview). This interchange suggested that the underlying mathematical idea was not clear to her, possibly implying that such understanding was a low priority for her. Having fun appeared to be the ultimate goal of mathematics teaching.

A comment by Tina also suggested that having fun in mathematics lessons was the central focus:

Something else that I find fascinating is the students' attitudes towards maths. I have learnt to keep the fact that we are doing maths a big secret. Never do I say the word maths; it is always a game or something fun and interesting. I am amazed at the positive attitudes displayed toward a game when compared to the audible groan heard when I mention maths. Surely, such negative attitudes cannot be in students so young. (Tina, second interview)

While it is affirming to me, as a teacher educator, to know that my students want to provide enjoyable activities for their students in learning mathematics, these two quotations indicate that the notion of enjoyment does not seem to include the enjoyment gained from understanding a concept or the intellectual fun involved in developing an idea. It is a reminder to me to discuss 
with my students my personal sense that, while implementing an activity that is fun for students is important as a bridge to the mathematical idea being pursued, it should not be seen as an end in itself in the mathematics classroom.

\section{Thoughts about the Teacher Education Program}

While the preceding data indicate areas that our teacher education program needs to address further, there were many comments that were very positive about the program and the students' preparation for teaching. For the purposes of self-study, these data are not as useful. While they may affirm various approaches and subjects, they do not challenge our thinking and reframing of the subject. Consequently, I give less emphasis to these data in this article. However, a selection of comments about students' preparation follows to indicate the tone of the feedback.

[The teacher education course] gives you ideas for hands-on, which is so much more ME than doing textbook chalk and talk. ... If I hadn't had such positive experience at uni, I would have steered away from science and maths. I mean maths is a basic requirement, but I would have done very textbookish. It wouldn't have been very experimental or discovery. (Jo, interview).

Julie noted how much better prepared she was for the hands-on nature of the new syllabus than were some of the older teachers. She had just attended an in-service event on mathematics:

We had to cross-reference with our textbook, which some came unstuck with, and at the end they had comments and the main comment that kept coming through is "It's really hard to teach Space using the textbook, we've only just discovered this" and I am thinking "How could you only just discover this? They've been teaching 10 to 20 years, most of them. How could you not have?" (Julie, second workshop)

There were many similar comments indicating how the teachers had appreciated the hands-on and experiential way of learning mathematics that we modeled at university. While these were positive comments, they could also be seen as the problems that set up the issues in the previous sections, as they put the new teachers in potential conflict with more experienced teachers. 


\section{Being a New Teacher}

Even though the interview questions were not directed at this issue, the overwhelming nature of the job in the first year arose repeatedly in the interviews. Often, the teachers did not wish to talk about their experiences in mathematics lessons, but dwelt on critical incidents to do with being a beginning teacher, as in the following:

I think [school staff] should treat you more like you are just a beginning teacher. Like I found that hard at my school. They expect like you have been teaching for 10 years. And they expect you to know things, and you can't know things. Even down to little things

like where resources are. (Julie, second workshop)

As previously noted, Annie had a very difficult period in her first year because she found that all her attention was being directed to managing a child with a behaviour disorder. Her self-esteem was damaged by the experience and she felt that she was failing the entire class. Eventually, when she was at breaking point about half way through the year, she went to see her principal and broke down, weeping as she explained how difficult she was finding teaching. The principal had not been aware of her problems and immediately transferred the child to the parallel class taught by the Deputy Principal. Some 3 weeks later, the child was transferred to a special school for children with behaviour disorders. Once the child was no longer in Annie's class, her firstyear experience was transformed. Annie's experience highlighted for me both the difficulties and the lack of power that beginning teachers experience, as well as the importance of collegial support. It was a motivating factor in directing my future teaching and research to the area of early-career teaching.

\section{What Surprised Me?}

I had failed to anticipate a number of issues. The first issue was the moral imperative that we appeared to be instilling in our students: "Go out and teach like this and save the world." It appears that I had been quite evangelical in my approaches. I do believe in those approaches, just as I believe that teaching in the ways we model at university can break the cycle of 
indifference to and anxiety about mathematics. This kind of teaching can also address the lack of understanding of mathematics that many student teachers experience, but I had not anticipated the barrier of the school context. When my students became teachers and failed to teach in the ways we had discussed at university, they felt that they had failed us by not living up to the good-teacher image that we had developed together. I had not been aware of the tensions I was unwittingly creating for them by developing an image of the good teacher. Further, I became aware that my beliefs about how to teach mathematics in the primary school were not necessarily helpful to them as they encountered accepted practices in the primary school.

The second unanticipated issue was that, for most of the beginning teachers, the teaching of mathematics was not the issue. I had anticipated that the teaching of this subject would bring a number of complications and difficulties to the fore and it was for this reason that I initiated the study. What came up time and time again, however, were the difficulties of being a new teacher in the school: the overwhelming experience of the first year of teaching, the lack of support from experienced colleagues who were prepared to pass on to them all the most challenging students and the difficulties of finding and appropriately using resources. The task for our graduates became how to survive as a beginning teacher, not how to teach primary mathematics. The need to cope with the daily demands of teaching quickly displaced the goal of teaching mathematics in an engaging and reformist way.

\section{Implications for my Practice}

This study provided awareness of the constraints of the classroom which has led to a questioning and reframing of my approaches. While I believe that these experiential and collaborative ways of working are valuable ways to learn for the majority of students, I have become aware of the pitfalls of exchanging one kind of certainty for another. 
With the hope of avoiding the dogma about the nature of mathematics that has pursued my students from their years at school, I had developed a different type of dogma regarding the nature of good mathematics teaching. Consequently, in my teaching I use an internal voice that challenges me on a regular basis and forces me to question both whether I am acknowledging the constraints of the classroom sufficiently and whether I am setting up my students to fail by promoting an idealized version of a mathematics teacher.

To help me in my teaching, I have invited critical friends into my classrooms and engaged in discussion with them about approaches that we use in our teaching. By looking at how they teach, in different subject areas, I am able to reframe my views of what good teaching can look like. Hopefully, I am extending and broadening my views through this process and, by implication, extending the views of my students (Schuck, Aubusson \& Buchanan, 2008).

The process of reframing is dynamic and never-ending. I am constantly grappling with the issue of our students' idealism. I pose the question: Is it better to inspire students to want to go into the teaching workforce as agents of change or to help them through the initial period of survival by emphasizing compliance and conformity rather than innovation and change? Alternatively, should I be helping them through that initial period by being honest about the challenges that lie ahead and suggesting that they take small steps towards change rather than trying to act as revolutionaries?

\section{Modification of Program}

My awareness of the challenging and often overwhelming nature of the first years of teaching has led to my developing two subjects that are directly focused on these early experiences and ways of supporting them. One subject is being offered for the first time as an elective in our Bachelor in Education (Primary Education) program. It is intended for final-year students and focuses directly on the realities of the schools and classrooms where they will soon be teaching. The subject is described as follows in the university calendar: 
The subject will address some of the challenges that beginning teachers meet in their first year of teaching, including: interactions with parents, membership of the wider school community, collegial and professional interactions, and management of professional roles and responsibilities. Students will explore strategies that will assist them to thrive, rather than merely survive, as beginning teachers. The hidden curriculum of the primary school will be examined as a means of equipping students with repertoire of skills that will facilitate a smooth transition to becoming a professional primary school teacher. (UTS calendar, 2008).

The subject was offered for the first time in Spring Semester 2008 and feedback suggests that it was extremely valuable to students, so much so that many students, both inside and outside the class, have asked that it replace one of the core subjects in the last year of the 4-year degree.

The other new subject, Mentoring Beginning Teachers, was originally developed as a post-graduate subject for practicing teachers with a focus on developing skills for mentors in schools. In its first offerings, students in the subject worked with beginning teachers who were our recent graduates. The subject has now been renamed at Mentoring in the Workplace and broadened to include mentoring in other workplaces.

\section{Changes in my Work}

Apart from the changes in my teaching of mathematics education subjects, as discussed above, these studies have suggested a particular research pathway. As it became clear to me that, for the participants in the second study, it was not the teaching of mathematics but the experience of being a beginning teacher that was overwhelming, I realized that I could assist our students after their graduation in a number of ways. These included researching their experiences on leaving the university and disseminating the results to teacher educators and employing authorities. I am currently leading a team of researchers in a study sponsored by a major employing authority to investigate how best to retain effective early-career teachers. This project follows one in which a consortium of universities looked at the experiences of our respective graduates and what their 
experiences meant both for our institutions and for their future employment. Awareness of the importance of support and collegiality has helped me to support new academics on our staff and to initiate and convene support groups for different aspects of professional learning. The findings of the research inform my role as supervisor and mentor and give new impetus to my desire to be an empathetic and supportive colleague.

\section{Concluding Remarks}

I hope to continue to support for our students by highlighting the complexity of teaching and the constraints of the classroom, without becoming discouraging or overwhelming them with the difficulties that lie ahead. I also find it important not to set up our practices in the teacher education program as being in opposition to school practices. I acknowledge Buchanan's (2006) assertion that we have a privileged position in our teacher education courses and cannot expect our modeling of practice in this rarefied atmosphere to be transferable to the realities of the school classroom.

The tensions between helping students to become change agents and acknowledging the contexts in which they will teach are very real. This has led to far less confidence in my beliefs about how best to serve our students. I wish to continue to work with critical friends who will call me to account in my thinking about my teaching and compel me to confront the question of whether I am taking sufficient account of the context in which teachers find themselves. These self-study aspects of these projectsstudies have have forced me to reframe my thinking about how I teach and what I expect from my students.

The value of testing our teaching against the reality of the experiences of our graduates is immense. It can open our eyes to the important issues experienced by our graduates as it also suggests directions both for our teaching in teacher education programs and for ways of providing support for the new teachers once they leave our institutions.

\section{References}


Angus, M., Olney, H., \& Ainley, J. (2007). In the balance: The future of Australia's primary schools. Kaleen, ACT: Australian Primary Principals Association.

Bogdan, R., \& Biklen, S. (1998). Qualitative research for education: An introduction to theory and methods (3rd ed.). Boston: Allyn and Bacon.

Buchanan, J. (2006). Splashing in puddles? What my teaching and research tell me about my teaching and research. In P. Aubusson \& S. Schuck (Eds.) Teacher learning and development: The mirror maze (pp. 131-144). Dordrecht: Springer.

Jones, G. (2004). The impact of 20 years of research. In B. Perry, G. Anthony, \& C. Diezmann (Eds.) Research in Mathematics Education in Australasia, 2000-2003 (pp. 339-386).

Flaxton, Queensland: Mathematics Education Research Group of Australasia.

Lincoln, Y., \& Guba, E. (1990). Judging the quality of case study reports. Qualitative Studies in Education, 3, 53-59.

Lyons, T., Cooksey, R., Panizzon, D., Parnell, A., \& Pegg, J. (2006). Science, ICT and mathematics education in rural and regional Australia: The SiMERR national survey. Retrieved 12 November 2008 from http://www.une.edu.au/simerr/national_survey/index.html

Miles, M., \& Huberman, A. M. (1994). Qualitative data analysis: An expanded sourcebook. Thousand Oaks, CA: Sage.

National Council of Teachers of Mathematics (2000). Principles and standards for school mathematics. Reston, VA:National Council of Teachers of Mathematics.

Nisbet, S., \& Warren, E. (2000). Primary school teachers' beliefs relating to mathematics, teaching and assessing mathematics and factors that influence these beliefs. Mathematics Teacher Education and Development, 2, 34-47.

Schuck, S., Aubusson, P., \& Buchanan , J. (2008). Enhancing teacher education practice through professional learning conversations. European Journal of Teacher Education, $31,215-227$. 
Schuck, S. (2006). Evaluating and enhancing my teaching: What counts as evidence? In P. Aubusson \& S. Schuck (Eds.) Teacher learning and development: The mirror maze (pp. 209-220). Dordrecht: Springer.

Schuck, S. (2002). Using self-study to challenge my teaching practice in mathematics education. Reflective Practice, 3, 327-337.

Schuck, S. (1999). Teaching mathematics: A brightly wrapped but empty gift box. Mathematics Education Research Journal, 11(2), 109-123.

Schuck, S. (1998). Conversations of the three selves of the prospective primary mathematics teacher. Teaching and Teacher Education, 14, 703-714.

Schuck, S. (1996). Chains in primary teacher mathematics education courses: An analysis of powerful constraints. Mathematics Education Research Journal, 8(2), 119-136.

Strauss, A., \& Corbin, J. (1998). Basics of qualitative research: Techniques and procedures for developing grounded theory (2nd ed.). Thousand Oaks, CA: Sage.

University of Technology, Sydney (2008). UTS: Calendar 2008. Retrieved November 3, 2008 from http://www.calendar.uts.edu.au/

Walshaw, M., \& Anthony, G. (2007). Policy implementation: Integrating the personal and the social. Mathematics Teacher Education and Development, 8, 5-22. 